\title{
Sugar malabsorption in healthy neonates estimated by breath hydrogen
}

\author{
A C DOUWES, R F OOSTERKAMP, J FERNANDES, T LOS, AND A A JONGBLOED \\ Children's Department, Free University Hospital, Amsterdam, The Netherlands
}

SUMMARY Carbohydrate malabsorption in 110 healthy, term neonates was studied by estimating expired hydrogen $\left(\mathrm{H}_{2}\right)$ before and after a feed on day 6 or 7. Carbohydrate malabsorption was assumed to be present if the infant excreted $>20$ parts per million (ppm) $\mathbf{H}_{2}$. The frequency of carbohydrate malabsorption in 49 breast-fed infants was $25 \%(n=12)$, in 35 infants fed a $7 \cdot 5 \%$ lactose formula it was $31 \%(n=11)$, in 26 infants fed a formula containing $1 \%$ lactose and $7 \cdot 3 \%$ maltodextrin it was $15 \%(n=4)$. These differences in frequency were not significant. Peak $\mathrm{H}_{2}$ concentration of the malabsorbers in each group, indicating the degree of carbohydrate malabsorption, was 64,52 , and $32 \mathrm{ppm}$ respectively. The degree of carbohydrate malabsorption did not differ significantly between the breast-fed and the high lactose formula groups, but both groups differed from the low lactose group. $\mathrm{H}_{2}$ excretion was studied for 5 months in an exclusively breast-fed infant. In the first 2 months high concentrations were found and the infant produced 3-5 stools a day. In the next 3 months however, most $\mathrm{H}_{2}$ estimations were normal and only 1-2 stools a week were passed. With the introduction of solids, daily bowel movements promptly reoccurred. Frequency of carbohydrate malabsorption in newborn infants is fairly high and is primarily related to the lactose intake. The frequency and degree of carbohydrate malasorption were comparable in breast-fed infants and in infants fed on a high lactose formula; this differs from results previously reported.

The occurrence of carbohydrate malabsorption (CHM) in normal, term neonates on breast milk or cows' milk-based formulas, may be assumed from the finding of more than $0.5 \%$ reducing substances in the faeces, ${ }^{1-3}$ or from the finding of more than $0 \cdot 15 \mathrm{~g} / \mathrm{l}$ reducing substances in the urine. ${ }^{4}$ The mean 'normal' excretion of lactose in the urine of 88 neonates between the 3rd and 7th day of life ranges between 0.2 and $0.5 \mathrm{~g} / 1 .{ }^{5}$ Sugar chromatography on stools with excess reducing substances generally shows the presence of lactose, glucose, and galactose. ${ }^{2-3}$ This pattern is consistent with incomplete lactose absorption as nonabsorbed lactose is split by the faecal flora into its component monosaccharides. ${ }^{6}$ Lactose malabsorption has been reported to be more common in breast-fed than in bottle-fed infants, even if lactose concentration in the milk is similar. ${ }^{1-3}$ These findings may have practical implications from the nutritional point of view and may help to establish a nonpathogenic type of large bowel microflora. ${ }^{7-8}$ However, the reported differences of CHM in bottle- and breast-fed infants may have been affected by differences in bacterial fermentation of the nonabsorbed sugars and by contamination of the stools with lactose-containing urine.

It has been shown that malabsorption of lactose and other sugars can easily be detected by estimating $\mathrm{H}_{2}$ in expired air in adults $^{9-10}$ or children. ${ }^{11-14}$ Using a procedure for interval sampling of mixed expired air adapted for infants, ${ }^{15}$ we have studied the frequency and the degree of CHM in 110 newborn infants, fed on one of three feeding regimens. The main objective was to find out whether the reported difference in CHM between bottle-fed and breast-fed infants could be confirmed.

\section{Patients and methods}

We examined 110 healthy, term infants in the maternity ward of our hospital. Informed consent was obtained from all the parents. Each infant was fed exclusively one of three milks: breast milk $(\mathrm{n}=49)$, cows' milk-based formula containing $7.5 \%$ lactose (Almiron M2-B*) $(n=35)$, or $1 \%$ lactose and $7 \cdot 3 \%$ maltodextrin (Almiron $\mathrm{A}-\mathrm{B}^{*}$ ) $(n=26)$. The composition of each formula is shown

*Manufactured by Nutricia, Zoetermeer, the Netherlands. 
Table 1 Constituents of the milks used in this study (in $\mathrm{g} / 100 \mathrm{ml}$ ). Fats in the formula feedings were corn-oil derived

\begin{tabular}{llll}
\hline & Breast milk & Almiron M2-B & Almiron A-B \\
\hline Lactose & $6 \cdot 6-7 \cdot 1$ & $7 \cdot 5$ & 1 \\
Maltodextrin & - & - & 7.3 \\
Fat & $2 \cdot 9-3.5$ & 3.5 & 2.9 \\
Protein & $1 \cdot 1-1.4$ & 1.5 & 1.8 \\
\hline
\end{tabular}

in Table 1. Infants on mixed feeds were not studied, but breast-fed infants whose feeding had been supplemented with glucose solution during the first few days after birth were included. Mothers who breast fed their babies were instructed to avoid fruit and fruit juices on the day before and during the examination since fruit sugars may be excreted into the breast milk.

To avoid the influence of large differences in intakes of milk/ $\mathrm{kg}$, the actual body weights and ingested volumes of the feeds were recorded. In the breast-fed group ingested volume was estimated by test weighing the infant before and after the feed. Serial $\mathrm{H}_{2}$ estimations were done on day 6 or 7 , starting at 0900 hours, three hours after the first feed that day. The second breath sample was taken at 1000 hours (just before the second feed), the third at 1100 hours, and the fourth at noon. Duplicate breath samples were stored in Vacutainers for gas chromatographical analysis. Details of the procedure have been presented previously. ${ }^{15}$ In children with lactose malabsorption, an increase above the baseline value of $>10 \mathrm{ppm} \mathrm{H}_{2}$ correlated positively with the occurrence of clinical symptoms. ${ }^{16-17}$ Since the frequent feedings in the study group did not allow $\mathrm{H}_{2}$ excretion to be measured during fasting, and this is below $10 \mathrm{ppm}$ in older children (R G Barr, 1979, personal communication), a total concentration of $20 \mathrm{ppm} \mathrm{H}_{2}$ in mixed expired air was assumed to be a safe indication for the presence of CHM in these neonates.

\section{Results}

All 27 infants with CHM were white, $7(26 \%)$ of them weighed more than $3500 \mathrm{~g}, 13(48 \%)$ weighed more than $3000 \mathrm{~g}$, and $7(26 \%)$ weighed more than $2500 \mathrm{~g}$, the lowest weight being $2575 \mathrm{~g}$. No infant had diarrhoea although all infants passed at least two loose stools a day. The mean volume of milk ingested $(\mathrm{ml} / \mathrm{kg})$ did not differ between the three feeding groups and only small individual variations were found.

Most of the infants with CHM had raised $\mathrm{H}_{2}$ concentrations in the first breath sample. This was generally followed by a further increase, although in some infants the concentration remained more or less constant, and 2 infants had decreasing concentrations towards the end of the sampling period. Peak $\mathrm{H}_{2}$ excretion for each infant is recorded in Fig. 1. The frequency of CHM in the 49 breast-fed infants was $25 \%(n=12), 31 \%$ in the 35 infants fed $7.5 \%$ lactose formula $(n=11)$, and $15 \%$ in the 26 infants fed $1 \%$ lactose formula with $7 \cdot 3 \%$ maltodextrin $(n=4)$. These frequencies are not statistically different. The relative degree of $\mathrm{CHM}$, measured as peak $\mathrm{H}_{2}$ excretion, was no different for breast-fed infants than for those on the $7.5 \%$ lactose furmula. But both of these groups had a significantly higher degree of CHM compared with the group on $1 \%$ lactose and $7 \cdot 3 \%$ maltodextrin formula $(P<0.01$, Table 2).

$\mathrm{H}_{2}$ excretion in the breast-fed infant during the

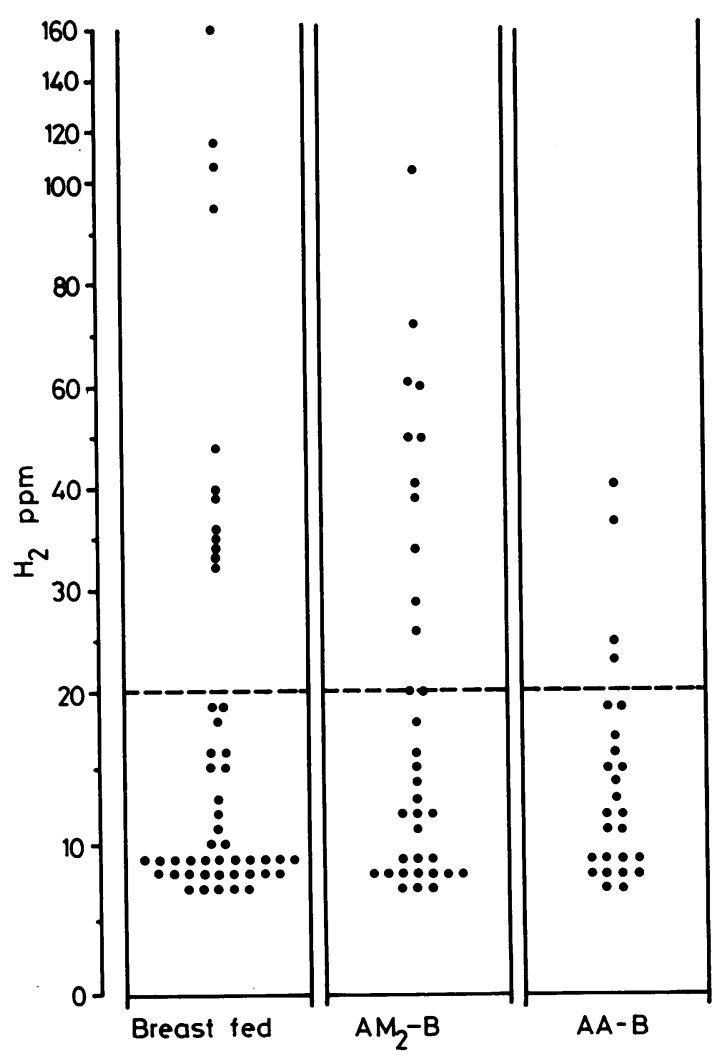

Horizontal bar gives upper normal value.

$\mathrm{AM}_{2}-\mathrm{B}=7 \cdot 5 \%$ lactose formula group; $\mathrm{AA}-\mathrm{B}=1 \%$ lactose with $7 \cdot 3 \%$ maltodextrin formula group.

Fig. 1 Peak $\mathrm{H}_{2}$ excretion in 110 normal, 6- or 7-day-old-infants on one of three feeding regimens. 
first 150 days of life changed during the day (Fig. 2), and varied greatly on different days (Fig. 3). The highest concentrations however, were found in the first 2 months. Stool frequency in the first 2 months was 3-5 a day. In the next 3 months, while the baby was still being exclusively breast fed, $\mathrm{H}_{2}$ excretion became normal or was moderately raised (Fig. 3). Only 1-2 stools a week were passed in the last 3 months and no sign of constipation occurred. Introduction of solids at age 6 months immediately resulted in daily passage of 1-2 well-formed stools.

Table 2 Frequency and relative degree of carbohydrate malabsorption in three groups of neonates on different feeding regimens

\begin{tabular}{llll}
\hline & $\begin{array}{l}\text { Breast milk } \\
(n=49)\end{array}$ & $\begin{array}{l}\text { Almiron M2-B } \\
(n=35)\end{array}$ & $\begin{array}{l}\text { Almiron } A-B \\
(n=26)\end{array}$ \\
\hline $\begin{array}{l}\text { No of infants (\%) } \\
\begin{array}{l}95 \% \text { confidence } \\
\text { limits for per- } \\
\text { centage malab- }\end{array}\end{array}$ & $12(25)$ & $11(31)$ & $4(15)$ \\
$\begin{array}{l}\text { sorbers } \\
\begin{array}{l}\text { Mean ppm } \mathrm{H}_{2} \\
\text { malabsorbers }\end{array}\end{array}$ & $15-39$ & $18-49$ & $7-34$ \\
SD & 43 & 52 & $32(\mathrm{P}<0.01)$ \\
\hline
\end{tabular}

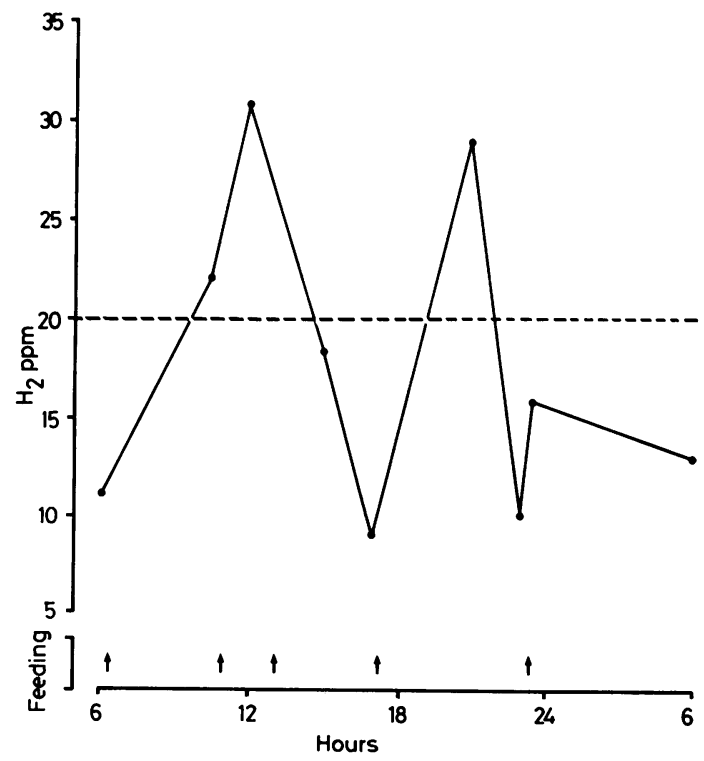

Feedings indicated by arrows. Horizontal bar gives upper normal value.

Fig. 2 Variation in $\mathrm{H}_{2}$ excretion during a 24-hour period in an exclusively breast-fed infant, aged 28 days.

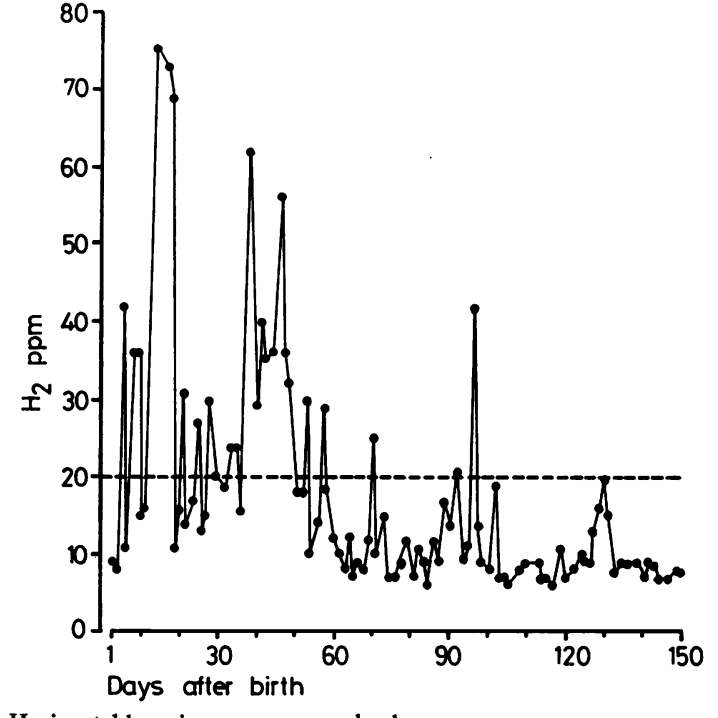

Horizontal bar gives upper normal value.

Fig. $3 \mathrm{H}_{2}$ excretion over 5 months in an exclusively breast-fed infant.

\section{Discussion}

This study confirms earlier observations, based on the finding of excess reducing substances in the stools $(>0.5 \%)$ or in the urine $(>0.15 \mathrm{~g} / \mathrm{l})$, that many neonates have some degree of CHM. ${ }^{1-4}$ The amount of sugars found in excreta gives some indication of the degree of CHM; this tended to be higher in breast-fed infants than in bottle-fed ones. ${ }^{2-3}$ Conclusions about the different degree of CHM between these groups have not been made.

It has been shown previously that $\mathrm{H}_{2}$ production is primarily related to the amount of fermentable substrate in the colon ${ }^{10}$ and this amount can be calculated from the expired $\mathrm{H}_{2} \cdot{ }^{18} \mathrm{H}_{2}$ response to the same dose of lactose may differ considerably between individual lactose malabsorbers, ${ }^{19}$ yet, the mean $\mathrm{H}_{2}$ response for a group of lactose malabsorbers to different doses of lactose differs significantly. It therefore seemed justified to use mean $\mathrm{H}_{2}$ concentrations for different feeding groups to find out the effect of diet on the degree of CHM. Unlike reports based on an estimation of faecal sugar, the degree of CHM as shown by mean $\mathrm{H}_{2}$ response did not differ between breast-fed infants and those on the $7.5 \%$ lactose formula, but CHM in both these groups was different from that in the group on the $1 \%$ lactose $7 \cdot 3 \%$ maltodextrin formula $(P<0.01)$.

Reports concerning the frequency of $\mathrm{CHM}$ in neonates are conflicting, and figures range from 0 to $50 \%{ }^{421}$. The precise frequency of $\mathrm{CHM}$ in neonates is difficult to establish as CHM may be 
present intermittently, as judged from the lactose content in urine ${ }^{4}$ and the excretion of $\mathrm{H}_{2}$ (Figs 2 and 3 ), and data from former studies as well as from this one are cross-sectional (Fig. 1). The actual frequency may therefore be considerably greater than these studies suggest. This suggestion is supported by the findings of our longitudinal study (Fig. 3). A relationship may exist between CHM and frequency of defecation; this is suggested by the pronounced decrease in stool frequency, synchronous with the decreasing concentrations of expired $\mathrm{H}_{2}$ after age 2 months (Fig. 3).

Lactose is often implicated as the major source of excess faecal and urinary sugar in newborn infants ${ }^{1-5}$ although other sugars have also been found. ${ }^{2-3}$ The accumulating evidence for lactose malabsorption in a considerable proportion of newborn infants seems to contradict the finding that brush border lactase activity is fully mature by the time of birth although its maximum is reached only shortly before delivery. ${ }^{20}$ Presumably the total splitting capacity of the neonatal small bowel is reduced because in these infants the surface area is smaller than in older infants. Previous studies that have been based on an estimation of faecal sugar have stressed the influence of the nature of the feeding, and have suggested that frequency and degree of CHM in breast-fed infants were higher than in formula-fed neonates, even when these formulas contained lactose in amounts comparable with human milk. ${ }^{1-38}$ Our study failed to confirm this interpretation since frequency of abnormal $\mathrm{H}_{2}$ excretion in breast-fed infants did not differ from that in bottle-fed infants, and was even lower in the breast-fed group compared with the high lactose formula group (Table 2).

Our findings indicate that CHM in healthy, term neonates is primarily due to an age-related maturation process of lactose digestion and absorption, rather than to the nature of the feeding.

We thank Dr H Konings and Dr J de Wit for help with the collection of breath samples, Ludy van Winsen for help with the analysis, the obstetric ward of the Free University Hospital, Amsterdam, for kind co-operation, J J Buis and C S Mansvelder for technical assistance, Dr H M Berger for help with the manuscript, Helma van Boxtel for secretarial help, and the Departments of Medical Illustration of the Sophia Children's Hospital, Rotterdam, and the Medical Faculty of the Free University, Amsterdam, for the drawings.

\section{References}

1 Davidson A G F, Mullinger M. Reducing substances in neonatal stools detected by Clinitest. Pediatrics 1970; 46: 632-5.
2 Counahan R, Walker-Smith J. Stool and urinary sugars in normal neonates. Arch Dis Child 1976; 51 : 517-20.

3 Whyte R K, Homer R, Pennock C A. Faecal excretion of oligosaccharides and other carbohydrates in normal neonates. Arch Dis Child 1978; 53: 914-5.

4 Haworth J C, McCredie D. Chromatographic separation of reducing sugars in the urines of newborn babies. Arch Dis Child 1956; 31 : 189-90.

5 Bickel $\mathrm{H}$. Mellituria, a paper chromatographic study. $J$ Pediatr 1961 ; 59: 641-56.

- Lindquist B L, Wranne L. Problems in analysis of faecal sugar. Arch Dis Child 1976; 51 : 319-21.

7 Bullen C L, Tearle P V, Willis A T. Bifidobacteria in the intestinal tract of infants: an in-vivo study.J Med Microbiol 1976; 9: 325-33.

8 Heine W, Zunft H J, Müller-Bethow W, Grütte F K. Lactose and protein absorption from breast milk and cows' milk preparations and its influence on the intestinal flora. Acta Paediatr Scand 1977; 66: 699-703.

9 Calloway D H, Murphy E L, Bauer D. Determination of lactose intolerance by breath analysis. Am J Dig Dis 1969; 14: 811-15.

10 Levitt M D. Production and excretion of hydrogen gas in man. N Engl J Med 1969; 281 : 122-7.

11 Maffei H V L, Metz G, Bampoe S V, Shiner M, Herman S, Brook C G D. Lactose intolerance detected by the hydrogen breath test in infants and in children with chronic diarrhoea. Arch Dis Child 1977; 52: 766-71.

12 Fernandes J, Vos C E, Douwes A C, Slotema E, Degenhart H J. Respiratory hydrogen excretion as a parameter for lactose malabsorption in children. Am J Clin Nutr 1978; 31 : 597-602.

13 Perman J A, Barr R G, Watkins J B. Sucrose malabsorption: diagnosis by interval breath hydrogen determination. J Pediatr 1978; 93: 17-22.

14 Douwes A C, Fernandes J, Jongbloed A A. Diagnostic value of sucrose tolerance test in children, evaluated by breath hydrogen measurement. Acta Paediatr Scand 1980; 69: 79-82.

15 Douwes A C, Fernandes J, Rietveld W. Hydrogen breath test in infants and children: sampling and storing expired air. Clin Chim Acta 1978; 82: 293-6.

16 Barr R G, Becker M C, Heymann P W, Watkins J B. Lactose malabsorption, abdominal pain, and lactose ingestion in a multiethnic school population (abstract). Gastroenterology 1978; 74: 1006.

17 Douwes A C, Fernandes J, Degenhart H J. Improved accuracy of lactose tolerance test in children, using expired $\mathrm{H}_{2}$ measurement. Arch Dis Child 1978; 53: 939-42.

18 Bond $\mathrm{J} \mathrm{H}, \mathrm{Jr}$, Levitt $\mathrm{M}$ D. Use of pulmonary hydrogen $\left(\mathrm{H}_{2}\right)$ measurements to quantitate carbohydrate malabsorption.J Clin Invest $1972 ; 51$ : 1219-25.

19 Payne-Bose D, Welsh J D, Gearhart H L, Morrison R D. Milk and lactose-hydrolyzed milk. Am J Clin Nutr 1977; 30: $1799-810$.

20 Grand R J, Watkins J B, Torti F M. Development of the human gastrointestinal tract: a review. Gastroenterology 1976; 70: 790-810.

21 Soeparto P, Stobo E A, Walker-Smith J A. Role of chemical examination of the stool in diagnosis of sugar malabsorption in children. Arch Dis Child 1972; 47: 56-61.

Correspondence to Dr A C Douwes, Department of Paediatrics, Acadamisch Ziekenhuis der Vrije Universiteit, De Boelelaan 1117, 1007 MB Amsterdam, The Netherlands.

Received 21 August 1979 